\title{
GRAMATICALIZAÇÃO DE ADJETIVOS EM ADVÉRBIOS EM LÍNGUA PORTUGUESA UMA VISÃO FUNCIONALISTA DO FENÔMENO MORFOSSINTÁTICO
}

\author{
Rodrigo Freire é professor de língua portuguesa quadro efetivo do Estado do Rio de Janeiro e mestrando em Estudos Linguísticos \\ na UFF. \\ E-mail: freirerod@yahoo.com.br
}

\begin{abstract}
Resumo
$\mathrm{O}$ presente trabalho visa investigar o fenômeno conhecido por adverbialização, comum na classe morfológica dos adjetivos em língua portuguesa. Este trabalho, considerando o termo abraçado pela linguística funcional denominado Gramaticalização, visa buscar explicações para este fato na linguística geral e nas gramáticas tradicionais, essencialmente, apontando as explicações plausíveis e as falhas metodológicas presentes nos textos dos principais autores acerca do tema.
\end{abstract}

\section{Abstract}

The present article studies the phenomenon known as adverbialization, common in the morphologic category of adjectives in Portuguese. This work, considering the term adopted by functional linguistics named grammaticalization, aims at searching explanations for this event in general linguistics and in traditional grammar, mainly, showing possible explanations and methodological failures found in the main authors' texts about the subject.

\section{Introdução}

O presente trabalho visa apresentar, primordialmente sob a ótica funcionalista, uma análise do problema da adverbialização de adjetivos na língua portuguesa contemporânea, expondo a problemática e as diferentes visões e contradições entre alguns setores da linguística e da gramática em relação a esta área de investigação, que pouco abrigo encontra no ensino de língua materna no âmbito escolar.

O tema da gramaticalização de adjetivos vem recebendo especial atenção pelos estudiosos da linguagem. Cada vez mais vemos uma substituição de certas palavras que funcionariam sem problema no corpo do discurso como advérbios construídos com o sufixo -mente por adjetivos com papel de adjunto adverbial (ou adverbal segundo a nova terminologia a ser mostrada a seguir). Neste estudo serão mostradas e criticadas a supracitada posição dos linguistas e gramáticos, as lacunas deixadas pela tradição gramatical e as considerações que penetram ganhando relativa força nos estudos linguísticos mais inovadores.

Este artigo pretende analisar uma possível tendência de mudança linguística no discurso tanto popular quanto culto, tendência esta que não encontra seu espaço dentro 
das salas de aula e nos livros didáticos, configurando-se como uma clara defasagem na formação metodológica dos cursos de letras.

Assim, este artigo analisa e propõe estratégias de aplicação em sala de aula para preencher esta lacuna, citando métodos que consideram a flutuação categorial das duas classes de palavras,.aplicados com êxito em sala de aula

Vale ressaltar que este fenômeno se apresenta praticamente indistinto nas classes sociais brasileiras, fato que não estigmatiza nem exclui determinado grupo e determinada variante, mas fortifica a tese de que estamos perante um fenômeno abrangente que se insere no conceito de inovação e na questão da sintaxe regida por "uma questão de uso e não de princípios" (Bagno, 1999, 15). Assim, tornam-se pertinentes as palavras do linguista Jakobson (1970, p. 23) que afirma: "A Linguística interessa-se pela linguagem em todos os seus aspectos - pela linguagem em ato, pela linguagem em evolução, pela linguagem em estado nascente, pela linguagem em dissolução".

\section{Uma primeira colocação acerca dos problemas englobando a linguística e a gramática tradicional}

A gramaticalização de adjetivos implica em um complexo processo morfossintático que se insere na ideia de "uso" apontada por Bagno. Este processo possui diversas terminações como a chamada "Conversão", adotada neste estudo por ilustrar bem a transformação sofrida pelo termo, que antes seria classificado como um sintagma adjetival (Sadj), para depois passar a sintagma adverbial (Sadv).

Outro fator que motivou esta pesquisa é a observação do fenômeno em línguas como o inglês e o francês, que curiosamente apresentam o mesmo fenômeno sendo este de origem latina e aquele de origem germânica.

Podemos ver estes fenômenos nas seguintes sentenças:

- $\quad$ She is the woman that speaks hard;

- $\quad$ My boss has walked fast into his office;

E não encontramos nestes casos as sentenças formadas com o sufixo -ly de advérbio:

- $\quad$ She is the woman that speaks hardly;

- $\quad$ My boss has walked fastly into his office;

Na língua francesa ocorre o mesmo fenômeno:

- $\quad$ Elle parle haut avec les garçons;

- $\quad$ Nous allons à la gare, on doit marcher rapide! 
Na língua francesa também se percebe a não utilização do sufixo -ment na formação de advérbios, sendo colocados em seu lugar um Sadj convertido.

Partindo dos exemplos citados nota-se que a gramaticalização de adjetivos em advérbios é um fenômeno que se apresenta além dos domínios restritos da língua portuguesa, por isso este artigo defende duas hipóteses básicas:

1. Ocorre no português brasileiro (PB) contemporâneo uma tendência à flutuação entre as duas classes, sendo impossível fazer uma distinção clara entre adjetivo e advérbio observando o termo descontextualizado;

2. As construções que possuem o sufixo -mente em sua constituição se apresentam com uma gradação muito menor na língua popular; ocorrendo mais em verbos de menor utilização no fluxo da linguagem, mostrando uma tendência à arcaização devido ao baixo fluxo de uso.

\section{Dos fatos gramaticais no português em sua variante brasileira}

Na língua oral corrente no Brasil, tomando como exemplo arbitrário a variante padrão carioca, não é de se estranhar construções dos tipos:

1. Ela fala grosso;

2. A moça falou nervosa;

3. As crianças dormem tranquilas;

4. A cerveja que desce redondo

Temos nestas construções exemplos vivos de Gramaticalização que se fortalecem mais na língua popular a cada dia. Entretanto percebe-se que certas construções apresentam um nível de ocorrência menor como:

1. Ela fala grossamente ${ }^{1}$;

2. A moça falou nervosamente;

3. As crianças dormem tranquilamente;

4. A cerveja que desce redondamente.

Entre os exemplos citados acima podemos medir a frequência das ocorrências entre as concorrentes realizáveis: Ela fala grossamente x Ela fala grosso e A cerveja

\footnotetext{
${ }^{1} \mathrm{O}$ sufixo -mente é uma inovação românica. Já no latim existiam paráfrases do tipo sedula mente, pronta mente, devota mente. Mas mente ainda não é um sufixo. Trata-se de um ablativo do substantivo mens, tis. Devemos ao gênero deste substantivo a atual regra de formação dos advérbios com sufixo - mente que se junta à forma feminina do adjetivo: tranquilo > tranquilamente. 
que desce redondo $x$ A cerveja que desce redondamente. Nestes grupos encontramos desde construções vigentes na língua até construções que com o passar do tempo conseguem menos falantes adeptos.

Este fenômeno observado na variante contemporânea pode ser abordado por conceitos teóricos como Lei do Menor Esforço, Inovação Linguística etc. Neste trabalho, essa mudança (ou inovação) será analisada através dos achados da linguística funcional em sua vertente norte americana.

\section{A flutuação entre as classes gramaticais}

Para analisar esta problemática, o linguista Thomas (1969, p. 47) fez um interessante apontamento da "troca" de classes gramaticais em determinados contextos. Segundo o autor, "o adjetivo é encontrado em muitos casos que logicamente requereria um advérbio. (O termo) vacila entre concordância e desconcordância, entretanto são consideradas tais palavras adjetivos ou advérbios" ${ }^{2}$.

Esta breve consideração ilustra concisamente um dos tópicos de maior relevância deste trabalho: a flutuação existente entre as duas classes gramaticais e sua aplicação como determinante. Temos na obra de Thomas uma visão introdutória e panorâmica bem interessante do assunto, tratando deste com uma clareza nem sempre encontrada nos compêndios do meio acadêmico.

$\mathrm{O}$ autor descarta qualquer tipo de classificação prematura deslocada de contextualização, chegando a admitir uma neutralização nas propriedades gramaticais dos termos. Isto torna impossível de se definir as terminologias "adjetivo" ou "advérbio", gerando uma arbitrariedade pouco produtiva, fato que o linguista Givón não aceita em seus estudos.

Hummel (2002) também traz uma considerável apreciação sobre o tema. No artigo 'Considerações sobre os tipos Ela Fala Esquisito e Ela Chega Cansada no Português Coloquial” (2002), o autor observa o problema da ora isenção, ora presença da flexão abordado por Thomas e suas consequências na interpretação da sentença. Hummel traça uma separação entre termos de natureza adverbal (e não adverbial como chama atenção) e termos nominais (tradicionalmente conhecidos como predicativos) em oposições como:

\footnotetext{
${ }^{2}$ The adjective is found in many cases which would logically require an adverb. (It) vacillates between agreement and nonagreement, i.e., whether to consider such words adjectives or adverbs. Revista Escrita 

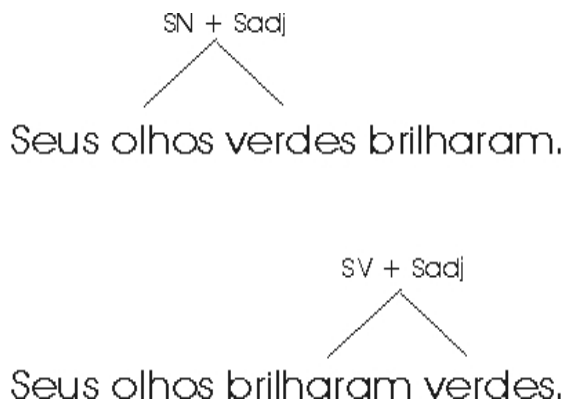

1. Seus olhos verdes brilharam

O termo anafórico verdes relaciona-se com o sujeito;

2. Seus olhos brilharam verdes

O termo anafórico verdes relaciona-se com o verbo.

Estes tipos de oposições são um dos pilares de sustentação do presente estudo. Seus problemas de interpretação percebidos em pesquisas feitas em salas de aula demonstram a problemática devido à mescla de funções de uma ambiguidade. Diante construções deste tipo, alunos apresentam uma deficiência ao diferenciar a qual termo da oração a função se aplica.

Esta problemática se agrava no momento em que a estes são impostas terminologias gramaticais, predominando em ambos os casos superescritos a definição "predicado verbo-nominal". Até que ponto se pode considerar o termo "verdes" referencial ao sujeito na oração 2 ? O fato é passível de uma longa discussão.

O linguista Hummel (2002, p. 45) apresenta um estudo contundente sobre o assunto em seus diversos artigos sobre a língua portuguesa. Familiarizado com a problemática gerada por esta ambiguidade o autor apresenta no esquema gráfico a seguir um exemplo de bifuncionalismo da palavra adjetiva em dois contextos específicos: 


\section{Adjetivo adnominal}

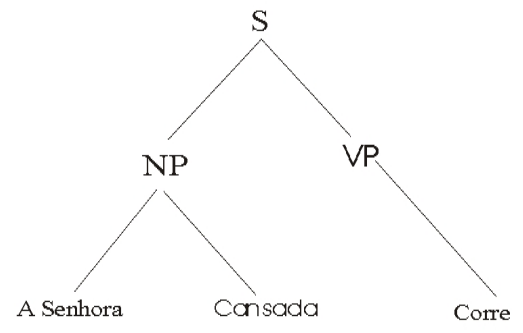

\section{Adjetivo adverbal}



Podemos exemplificar esta ambiguidade quando temos orações em que os verbos não se deslocam na sintaxe, nestes casos ficamos perante um caso ainda mais grave e ambíguo, como no exemplo:
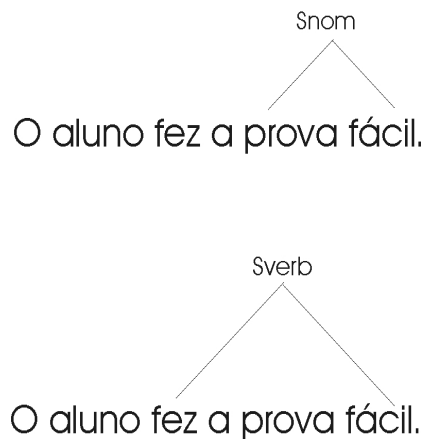

O caso é claro no exemplo anterior, o verbo não se desloca e respeita a sua posição clássica, vindo logo em sequência do sujeito (caso classificado pelo estruturalismo linguístico, e adotado pela tradição gramatical como ordem ou sequência canônica) gerando uma dificuldade maior de interpretação sobre o termo a qual o adjetivo se remete.

Com base nestes gráficos podemos aplicar a definição clássica de adverbialização proposta por Kurylowicz (1965, p. 69): "Gramaticalização consiste na expansão da extensão de um morfema avançando de uma forma léxica para uma forma 
gramatical ou de um status menos gramatical para mais gramatical, de um formato derivado para um formato flexional". 3

Assim temos, dentro desta definição, uma demonstração de um caso clássico de gramaticalização, que mescla a citação Thomas no traço de variar ou não em concordância; e na definição de Kurylowicz no traço do termo expandir suas características para fora de um campo pré-determinado.

Para se compreender como se dão os fenômenos de gramaticalização de termos, serão abordados, neste estudo, os passos evolutivos catalogados pelos linguistas Hopper e Traugott, processos estes abraçados largamente pela corrente funcional da linguística.

No esquema mostrado abaixo podemos citar os cinco princípios conceituais da gramaticalização de Hopper e Traugott (1993) aplicados ao fenômeno. Todos estes processos apresentam uma consonância simétrica com o conceito de "expansão" de Kurylowicz (1965, p. 69), principalmente no momento que este menciona uma "hierarquia" de formas mais e menos gramaticais apresentando consecutivamente valores de maior expressão na sentença.

São os conceitos (Hopper e Traugott, 1993, p. 169):

Estratificação: refere-se à coexistência de formas com função similar. Neste fenômeno a forma primitiva convive com a forma inovada (ou gramaticalizada), assim temos na língua um delimitado jogo de funções das formas definidos pela regência;

Divergência: caso à parte da estratificação, que trata dos fenômenos de gramaticalização que originam sufixos ou enclíticos, porém mantendo uma relação semântica próxima a forma base;

Especialização: trata do traço de obrigatoriedade que um termo pode assumir em um dado contexto devido à diminuição nas possibilidades de escolha. Na dada pesquisa será enfocada a tendência que certos adjetivos tendem a sofrer Especialização na sintaxe e buscar certas construções em que este será utilizado no contexto exclusivamente como adjetivo.

Persistência: um dos traços mais comuns das características elencadas por Hopper. Este se refere a resquícios semânticos que sobreviveram do termo original no termo inovado ou gramaticalizado. Por exemplo: o termo celibataire da língua francesa denomina solteiro. Na língua portuguesa, devido uma raiz erudita, o termo aportuguesou-se para a forma celibatário, que denomina o voto de abstinência sexual de religiosos, que logo gerou o substantivo celibato. Em ambas as ocorrências há a ideia implícita que tanto o solteiro e o religioso não possuem uma companheira do sexo oposto, logo há escassez da atividade sexual.

Noção de Persistência:

\footnotetext{
${ }^{3}$ Grammaticalization consists in the increase of the range of a morpheme advancing from a lexical to a grammatical or from a less grammatical to a more grammatical status, from a derivate format to an inflexional one 




Apresentando uma evolução diacrônica, temos uma forma base (A) e uma intermediária (B) e uma presente (C). A última forma inovada ou gramaticalizada traz resquícios diretos da forma $\mathrm{B}$ e esta apresenta a mesma característica em relação à forma $\mathrm{A}$. A forma $\mathrm{C}$ apresenta este subgrupo 2 como representação destes e resquício linguístico, e em sua formação morfológica pode apresentar traços do subgrupo 1, derivado da forma A na forma C. Assim a língua segue sua diacronia em uma progressão linear apresentando uma forte tendência de sempre trazer na formação de um dado vocábulo os "resquícios" da estrutura anterior.

No caso da gramaticalização de adjetivos podemos conferir uma forte presença desta teoria. Se usarmos como exemplo o adjetivo ríspido teremos, segundo a tradição gramatical, a formação do advérbio rispidamente. No vocábulo, percebemos uma leve alteração fonética, uma maior abertura labial e descanso da língua para converter o fone /o/ em /a/. Porém, desconsiderando a inserção do sufixo -mente, teremos, considerando a persistência, a total presença do vocábulo raiz, não se formando um vocábulo derivado deste. Assim, a persistência na adverbialização de adjetivos tende a manter estas formas raízes em sua plenitude, podendo se construir, sem problemas, um enunciado do tipo Ela falou ríspido com sua mãe.

Descategorização: fenômeno que, devido à descategorização de ítens gramaticalizados, causa o surgimento de formas híbridas. Ao se gramaticalizarem, as formas tendem a perder ou neutralizar marcadores morfológicos e as características sintáticas próprias das categorias passando a assumir o papel de adjetivo, particípio, preposição etc. Por exemplo: os nomes ingleses miss, mrs., e $m s$. usualmente não têm a capacidade de receber acessórios morfossintáticos como artigos, demonstrativos e possessivos e não figuram sozinhos a um participante do discurso.

As questões apresentadas nesta introdução teórica mostram um panorama da problemática referente ao assunto. As classes de palavras chegam, em certos contextos, a apresentar uma neutralidade gramatical e, dependendo de sua concordância, um jogo ambíguo problemático no fluxo da língua oral. Todas estas questões se afunilam neste emaranhado linguístico.

\section{A visão tradicional e a visão funcionalista de Givón}


Pesquisando o assunto dentro das obras e autores tradicionais da língua portuguesa na variante brasileira, o tópico da flexão na adverbialização de adjetivos esbarra numa clara deficiência quando se encontra perante esta bifurcação. Pouco se esclarece sobre o assunto em pauta, os gramáticos que abordam o tema mostram uma visão pobre do fenômeno, os níveis oscilam desde descrições sem parâmetros do assunto até a existência total de referência.

Bechara, em Lições de Português pela análise sintática (2003, p. 82), apresenta de uma forma comparativa o tema, porém pouco esclarece sobre o assunto, apresentando a problemática sem um desfecho conciso, apenas denomina o fenômeno como "Pontos de contacto entre o adjetivo e o verbo":

(...) Nem sempre é possível afirmar quando estamos diante de um advérbio e um adjetivo. A distinção se dá quando o sujeito está no feminino ou no plural, onde a flexão nos leva a melhor interpretar o termo como adjetivo, e em análise sintática como predicativo.

O autor cita como exemplo o fragmento Vamos falar sérios. A hipótese soa um tanto artificial para falantes brasileiros, já que temos já lexicalizados no português coloquial expressões como Fala sério!,É nós!, Com certeza!. E não suas variantes de raiz adverbiais per si como Fale seriamente!, Somos nós e Certamente!. A hipótese de se analisarem estas construções somente por estruturas do Português Europeu torna-se inviável, já que estas modalidades se distanciam cada vez mais do colóquio do português brasileiro.

Outro autor a abordar o caso de forma reconhecidamente superficial é Perini (2003, p. 24). Em sua Gramática Descritiva do Português, o linguista traz a problemática da falta de concordância entre termos sem esboçar nenhum tipo de discussão:

"Um outro problema ligado à identificação do complemento do predicado provém de frases como Cerveja é bom para lavar o cabelo.

Essas construções são de funcionamento misterioso, pois o complemento é passível de concordância e, no entanto, esta é bloqueada:

*Cerveja é boa para lavar o cabelo.

Isso parece acontecer somente quando o sujeito é representado por um núcleo sem nenhum termo acompanhante:

Essa cerveja é boa para lavar o cabelo;

*Essa cerveja é bom para lavar o cabelo.

Este problema deverá ficar de lado à espera de estudo que o esclareça."

O próprio autor deixa "este problema de lado" e não traça nenhuma teoria mínima acerca da estrutura. Sequer os termos "adverbialização" e "gramaticalização", bem popularizados até entre os gramáticos de formação mais tradicional, são mencionados no curto parágrafo dedicado à análise do fenômeno. A atribuição de "funcionamento misterioso" distancia claramente o problema do seio da gramática, 
gerando uma impressão de caso insolúvel e extraordinário, e mesmo trazendo uma pequena observação sobre a participação de termos marginais determinantes na flexão de gênero, pouco se pode concluir.

Mais clara é a visão do assunto de Cunha e Cintra (1985, p. 258):

“'D. Felismina sorriu amarelo' (Machado de Assis);

'Tinham-se habituado a falar baixo' (C. de Oliveira);

As palavras amarelo e baixo são advérbios”.

Embora o adjetivo adverbializado deva permanecer invariável, não faltam abonações, mesmo em bons autores, de sua concordância com o sujeito da oração, fato justificável pela ampla zona de contato existente, no caso, entre o adjetivo e o advérbio.

Cunha e Cintra (1985) fazem uma releitura concisa da visão bechariana acerca do fato. É curioso notar que dos textos utilizados como exemplo, apenas neste o fenômeno apresenta nomenclatura explícita, sinal de aceitação da ideia de um processo sintático-transformacional. Segundo os autores o fator principal para esta ocorrência provém de uma "zona de contato" entre as classes. Não são delimitados parâmetros maiores sobre esta zona virtual, porém a ideia se encaixa com a proposta de mobilidade proposta por Hummel na figura 1 supracitada.

Outro traço que ressalvam os autores é a não concordância do termo. Este apresenta uma espécie de "licença" para ocorrer, devido ao contexto dado. Seria esta desconcordância resultado de uma possível neutralização? Não se menciona o termo "neutralização" em nenhuma dos exemplos citados.

A questão da bilateralidade das classes gramaticais foi abordada de forma igualitária pelos gramáticos britânicos Quirk \& Greenbaum (1998, p. 136). Para estes, as classes possuem uma relação tamanha que não podem ser tratados por prismas diferentes, a flutuação de classes ou seu bifuncionalismo é admitido abertamente. $\mathrm{Na}$ introdução do capítulo Characteristics of the adjective fica explicado:

Não podemos dizer se uma palavra é um adjetivo olhando para ela isolada: a forma não necessariamente indica sua função sintática. (...) Nem podemos considerar um adjetivo considerando meramente flexões ou afixos que o termo permitirá. (...)

Certos itens que funcionam como adjetivos também são usados para definir de alguma forma o processo denotado pelo verbo. Este é um típico uso de advérbios, por exemplo, alto e claro em Ele falou alto e claro.

Para explicar as mudanças nas dadas estruturas, os funcionalistas Martelotta e Areas (2003, p. 28) reapresentam as premissas do funcionalista Givón, que serão base teórica de suma importância para o desenvolvimento desta abordagem:

1. A linguagem é uma atividade sociocultural,

2. A estrutura serve a funções cognitivas e comunicativas;

3. A estrutura é não arbitrária, imotivada e icônica; 
4. Mudança e variação estão sempre presentes;

5. O sentido é contextualmente dependente e não-atômico;

6. $\quad$ As categorias não são discretas;

7. A estrutura é maleável e não rígida;

8. As gramáticas são emergentes;

9. As regras de gramática permitem algumas exceções.

Muitas destas premissas afunilam-se com o fenômeno estudado. As principais observações propostas por Givón que se fitam com perfeição dentro deste fenômeno de gramaticalização são: o tópico 4, que traz uma forte influência dos primórdios da linguística funcional, a sociolinguística de Labov; o tópico 7, que solidifica a ideia de maleabilidade (ou flutuação), endossando a teoria de Thomas e Quirk \& Greenbaum; e, finalizando o tópico 9, que complementa o tópico 7, sendo que uma classe que é originalmente considerada como adjetivo pela gramática tradicional permite-se "abrir uma exceção" e figurar como adjetivo.

Mas como seria essa aplicação nas salas de aula? O ensino de língua portuguesa, fortemente influenciado pela tradição gramatical ensina as 10 classes de palavras ao aluno de uma forma rígida e elencada, por muitas vezes fazendo com que o aluno se preocupe em decorar uma lista e não a compreender conceitos. Analisando as situações de sala de aula e conversando com colegas, percebe-se uma forte defasagem no ensino relativo à morfossintaxe.

Uma experimentação proveitosa realizada em salas de aula de $2^{\circ}$ segmento, turmas de $6^{\circ}$ e $7^{\circ}$ ano, que estudam a introdução à morfologia prevista no currículo mínimo proposto pelo Estado do Rio de Janeiro, está justamente na apresentação destas classes de forma flexibilizada no ensino da nomenclatura adjetivo x advérbio, partindo dos conceitos iniciais de substantivo e verbo. Vejamos o exemplo aplicado em sala de aula:

Partindo do ponto em que palavras de "grupos semelhantes" podem ter funções diferentes na frase:

a) Base no substantivo (após revisar o conceito) - homem grosso, tarefa difícil, pizza doce;

Diálogo com a classe: notamos aqui que o termo se liga a um substantivo, ou seja, dá uma característica, logo, nessa situação esta palavra é um adjetivo.

b) Base no verbo (após revisar o conceito) - O homem fala grosso, político que fala difícil e bonito; ela sorriu doce (ou docemente);

Diálogo do professor com a classe: neste caso o termo se liga a um verbo, ou seja, muda de função, temos agora um advérbio. Para entender bem essas palavras basta associar a quem se liga, se for a um substantivo será um adjetivo, se for a um verbo será um advérbio. 
Esta técnica de ensino, livre de uma listagem pré-determinada, conduz o aluno a compreender o conceito dentro da oração e sua funcionalidade, sem apelar para a um tipo de pré-programação de classes de palavras rígidas, invariantes, como se nota nos exercícios do tipo "complete as lacunas".

\section{Referência do adjetivo adverbial ao sujeito temático do verbo: um caso aparte de gramaticalização de adjetivos no português escrito}

Até agora foram analisadas formas sintáticas que se remetem aos sujeitos estruturais das orações, geralmente figurados por agentes animados, fato comum na linguagem coloquial portuguesa e novilatinas. Estes adjetivos nem sempre precisam de um sujeito explícito ou gramatical para funcionar, porém devido à complexibilidade semântica desta construção, esta não encontrou largo abrigo na língua falada do dia-adia.

Este fato pode ser notado quando encontramos uma forma infinitiva substantivada e seu adjetivo adverbal cumprindo o papel de seu determinante: "Por estes barracões repousam os operários (...) só a esteira no chão, o dormir vestido, a capa por inteiro agasalho (...)" (Hummel, 2002, p. 83)

$\mathrm{Na}$ oração, temos um sujeito gramatical explícito. O termo os operários, que pelo desdobramento coesivo e coordenado faz-se notar que a oração mostra a dura rotina de trabalho dos operários que construíram o convento de Mafra.

Como se trata de um processo de substantivação do verbo em que este também flutua entre duas classes gramaticais, temos uma nítida influência no termo vestido, que remete a este substantivo, o qual não atua como sujeito gramatical, mas faz alusão aos operários, agentes da ação de dormir, logo temos o termo vestido em referência aos operários e não ao verbo somente.

Também devemos considerar as demais variantes do termo vestido, tanto fazendo referência ao sujeito implícito quanto fazendo referência ao sujeito gramatical ou estrutural:

1.a:Os operários dormem vestidos.

1.b:O fato de os operários dormirem vestidos.

1.c:O dormir vestido dos operários.

1.d:O dormir vestido.

Estes exemplos mostram o perfeito funcionamento do adjetivo adverbal sem a presença do sujeito gramatical (como em eles dormem vestidos), tampouco semiexplícito (como em dormem vestidos), basta que o verbo inclua um sujeito semântico (ou tácito na terminologia de Hummel), também classificado como sujeito temático.

Não só o infinitivo apresenta este tipo de fenômeno, a forma verbal gerúndio também apresenta em determinados casos esta tendência do adjetivo: 
2.a: "Virgínia podia ver as grossas pernas de Luela pendendo flácidas da cama"

2.b: "Revia-se com extraordinária nitidez correndo alucinada pelo pátio"

2.c: "Fez uma espécie de cabeleira brotando emaranhada em todos os sentidos"

Nestas orações, os adjetivos adverbais referem-se aos sujeitos temáticos ou implícitos dos verbos pendendo, correndo e brotando. Nestes casos específicos, todos os adjetivos adverbais são flexionados em gênero feminino, por seguirem uma lógica siléptica inclusa naturalmente no conteúdo semântico do verbo: em 2.a, o termo flácidas concorda com seu sujeito feminino: o objeto direto as grossas pernas de Luela; em 2.b, a própria flexão do adjetivo adverbal mostra que há um elemento feminino implícito no sujeito da oração (que mostra-se oculto), assim podemos calcular que se fosse utilizado um pronome reto na sua função normativa de sujeito na oração poderíamos ter a oração: Ela revia-se com extraordinária nitidez correndo alucinada pelo pátio (...), explicitando a flexão de gênero do termo em questão. Já em 2.c, o caso não é tão polêmico, temos o termo cabeleira em perfeita consonância com o verbo brotando, gerando a flexão mostrada.

\section{Conclusão}

A larga gramaticalização de adjetivos no português brasileiro toma de assalto a língua culta contemporânea, refletindo suas influências na literatura formal, texto jornalístico etc. Este traço linguístico do português contemporâneo vem ocorrendo com mais força não só no discurso culto, mas também no discurso popular, fato que comprova um fenômeno global dentro da língua portuguesa, sem se medir barreiras entre falante culto e falante inculto.

Nesse artigo foi analisado, majoritariamente, o fenômeno dentro de uma perspectiva funcional com base na vertente norte-americana, e esta aponta para duas conclusões: um possível caminho para uma arcaização de certas formas e a lexicalização de certas estruturas em dados contextos.

A primeira conclusão trata do caso das estruturas especificamente construídas com o sufixo -mente. Esta tese se baseia no baixo grau de ocorrências do tipo Ela fala deliciosamente e Ele é o homem que fala duro. Nestes contextos temos verbos que ocorrem largamente na língua do dia-a-dia, sendo uma espécie de tendência da língua a apresentar esta inovação nos verbos de maior fluência popular. Esta tese se enquadra perfeitamente no princípio funcionalista de que quanto mais uma forma é utilizada, mais esta tende a sofrer modificações.

A segunda conclusão, observando a análise das construções, é a tendência à lexicalização, ou seja, a concretização de uma dada forma na língua oral. Nesse caso, encontramos lexicalizadas estruturas do tipo Essa cerveja desce redondo e Maisena é bom para assaduras na pele, tendendo a se comportar desta forma afixada na 
linguagem em termos gerais, já que ambos exemplos apresentam não concordância na forma adverbializada, típico do fenômeno analisado.

Vale ressaltar também as lacunas que as gramáticas, os principais estudos referenciais da norma culta/padrão, deixam acerca do fato. Por muitas vezes o tema é abordado de forma confusa ou sem a devida importância, levando a um conflito entre os autores e gerando um problema para o professor de língua portuguesa, que busca nos compêndios bibliográficos subsídios para aplicação em sala de aula. Fica em aberto para gerações futuras de pesquisadores e professores de língua materna um tema tão fecundo que ainda não recebeu a devida atenção entre os autores eminentes.

\section{REFERÊNCIAS BIBLIOGRÁFICAS:}

AZEREDO, José Carlos de. Fundamentos de gramática do português. 3 ed.-Rio de Janeiro: Jorge Zahar Ed., 2004.

Iniciação à sintaxe do português. 7 ed. - Rio de Janeiro, Zahar Ed, 2001.

BAGNO, Marcos. Preconceito lingüístico. 34 ed. - São Paulo: Edições Loyola, 1999.

BASÍLIO, Margarida. "Flutuação categorial de base adjetiva do português falado". In: ILARI, Rodolfo. (Org.) Gramática do português falado vol. II: níveis de análise lingüística. São Paulo: Editora da Unicamp, 2002.

BECHARA, Evanildo. Moderna gramática portuguesa. 37 ed. Rio de Janeiro: Lucerna, 1999. 2003.

Lições de português pela análise sintática. 16 ed. - Rio de Janeiro: Lucerna,

CAMARA JR., Joaquim Mattoso. Estrutura da língua portuguesa. 36 ed. Petrópolis, Rio de Janeiro: Editora Vozes, 2002.

CASTELEIRO, João Malaca. Sintaxe transformacional do adjectivo. Lisboa: Instituto Nacional de Investigação Científica, 1981.

CUNHA, Celso. Nova gramática do português contemporâneo/ Celso Cunha, Luis F. Lindley Cintra. Rio de Janeiro: Nova Fronteira, 1985.

FONSECA, Joaquim. "Aspectos da sintaxe do adjectivo em português" em Línguas e Literaturas. Revista da faculdade de Letras do Porto II,6: 43-57, 1984.

FURTADO DA CUNHA, Angélica; OLIVEIRA, Mariângela; MARTELOTTA; Mário. (Orgs.). Lingüística funcional: teoria e prática. Rio de Janeiro: DP \& A, 2003.

GIVÓN, Talmy. Functionalism and grammar. Amsterdã/ Filadelfia: John Benjamins Publishing Company, 1995. 
HOPPER, Paul J.; TAUGOTT, Elizabeth C.. Grammaticalization across clauses. In:___. Grammaticalization. Cambridge University Press, 1993.

HUMMEL, Martin. "Considerações sobre os tipos Ela Fala Esquisito e Ela Chega Cansada no Português Coloquial e Literário do Brasil e de Portugal. In: ConfluênciasRevista do Instituto de Língua Portuguesa no. $24-2^{\circ}$ sem. 2002- RJ”.

"A conversão do adjetivo em advérbio em perspectiva sincrônica e diacrônica", Actas do sexto congresso da AIL - Associação Internacional de Lusitanistas (Rio de Janeiro, 08 a 13 de agosto de 1999). Disponível em: $<$ http//:www.geocities.com/ail_br/ail.html> .

JAKOBSON, Roman. Lingüística e Comunicação. 4ª ed. - São Paulo: Cultrix, 1970.

KOCH, Ingedore. A coerência textual. / Ingedore Koch, Luiz Carlos Travaglia. 13 ed. São Paulo: Contexto, 2001.

A coesão textual. 17 ed. São Paulo: Contexto, 2002.

KURYLOWICZ, Jerzy. The evolution of grammatical categories. Diogenes, 1965.

LIMA, Carlos. Gramática normativa da Língua Portuguesa. 38 ed. - Rio de Janeiro: José Olympio, 2000.

MIOTO, Carlos. SILVA, Maria Cristina Figueiredo. VASCONCELLOS, Ruth.

Novo manual de sintaxe. Florianópolis: Insular, $2^{\mathrm{a}}$ ed., 2005.

NEVES, Maria Helena de Moura. "Discurso e gramática no funcionalismo". Estudos Lingüísticos. São Paulo, no. 28 p. 30-40, 1999.

PERINI, Mario A. Gramática descritiva do português. São Paulo: Editora Ática, 2003.

QUIRK, Randolph \& GREENBAUM, Sidney. A University Grammar of English. $35^{\text {th }}$ reedition: Edeinburgh Gate, Harlow: Englad. Longman Press, 1998.

THOMAS, Earl W. The syntax of spoken Brazilian Portuguese, Nashville: Vanderbilt University Press, 1969.

TRAUGOTT, Elizabeth Closs: HEINE, Bernd. Approaches to grammaticalization. Amsterdã: John Benjamins, 1991. 